\title{
THE IMPLEMENTATION OF FLIPPED LEARNING 3.0 AND SELF-REGULATED LEARNING ON TENTH-GRADE STUDENTS' SPEAKING PERFORMANCE
}

\author{
M. Eggy Saputra \\ English Language Education, Universitas Pendidikan Ganesha \\ e-mail: eggysaputra206@gmail.com \\ Luh Diah Surya Adnyani \\ English Language Education, Universitas Pendidikan Ganesha \\ e-mail: surya.adnyani@undiksha.ac.id \\ Luh Gd Rahayu Budiarta \\ English Language Education, Universitas Pendidikan Ganesha \\ e-mail: budiartarahayu@gmail.com
}

\begin{abstract}
This study aimed to investigate the simple effect and interaction effect of flipped learning 3.0 (FL 3.0) and self-regulated learning (SRL) on students speaking performance in SMAN 1 Sukasada. This study was quasi-experimental research. Fifty-three tenth-grade students were the sample of this study that were divided into two groups, namely experimental and control groups. The data were collected through a post-test and survey. The data were analyzed using a two-way ANOVA. The result showed that flipped learning 3.0 did not give a significant difference on students' speaking performance, but the effect size showed a medium effect. On the other hand, SRL gave a significant difference on students' speaking performance between those who have high and low SRL. There was no interaction effect between FL 3.0 and SRL. Through the implementation of FL 3.0 and SRL, the students were stimulated to learn independently which can create their understanding and more active.
\end{abstract}

Keywords: speaking performance, flipped learning 3.0, self-regulated learning

\section{INTRODUCTION}

Speaking is a tool to communicate with others to expressing or exchanging though through using language that involves producing, receiving, and processing information (Köroğlu \& Çakır, 2017). It is the activity to express and use the target language through orally with appropriate vocabulary, pattern, and idea. Wael et al., (2018) state that, speaking performance is oral communication that involves other people in delivering the information by pronunciation the word. Speaking performance is a crucial part of English because it needs common sense to be understood by people. It refers to how the people use language and how they get feedback from the other (Handoko, 2017). It more focuses on the output of the person that conveying the idea of the message to the other person. 
By considering the importance of speaking performance, Indonesian students still lack speaking performance (Abrar et al., 2018). Indonesian students still have difficulty in using English in communication. Lack of vocabulary, bad pronunciation and shy are the main problem of them. They also prefer to use their mother tongue in learning English than using English itself. Besides, A survey by English First showed that Indonesian has a lower position in speaking English in South Asia. The lack of awareness of the importance of English is the main problem of this situation (Abrar et al., 2018). Besides, the Indonesian education is not good enough. There is limited time in learning space in which Indonesian education still focuses on delivering material than practicing language in class time.

As the importance of speaking performance, the success of the student's development of speaking performance comes from their responsibility in learning. The students' responsibility to control their learning goal, learning strategy, and monitor their goal progress is a significant aspect that describes the success of students' learning. It is known as self-regulated learning (K1zıl \& Savran, 2018). Self-regulated learning (SRL) is an active learning model that provides opportunities for students to organize their learning (Wang, \& Chen, 2019). It gives the responsibility to the students to take care of their learning. The students are free to decide what to learn, where to learn, when to learn, and how to learn. According to Geduld (2016), Self-regulated learning allows the students to control their learning markedly enhance their learning outcome. It involves students' metacognitive, motivation, and active participation in their learning. Students can control and set the goal of their learning that is a process and key factor of self-regulated learning.

Some researchers have found that self-regulated learning gave a positive effect on students' achievement. Carneiro, Lefrere, Steffens, and Underwood (2011) state that students that have good self-regulated learning are possible to achieve a better result of the study because they recognize a need to learn, make a wise choice to that need, and satisfy that need efficiently and affordably. The study by Geduld (2016) showed that high achievers students were more self-regulated than low achievers. It is necessary to create an awareness of the students about self-regulated learning to support their learning. Besides that, Wang \& Chen (2019) conducted a study about self-regulated learning to the students that used YouTube as learning media for learning English. As the result of this study, it assisted students in learning language. Their self-regulated learning increased while doing something that they liked.

Although the positive effect of self-regulated learning, the teaching model is also important in the development of students speaking performance. With the development of technology, flipped learning is one of the English teaching reforms which is a technology teaching method that changes the role of the class and home instruction (Bergman \& Sams, 2012). In the conventional method, students receive the material in class and practice exercise at home, but in flipped learning, those acts are flipped. Amiryousefi, (2019) states that, through flipped learning, the students receive the knowledge anywhere they want by watching the video, slides prepared, and the other material provided by the teacher. It enables the students to learn the concept of the material before the class activity. It also allows class activity more productive where the students have more time to practice inside the class, ask more questions, and engage more deeply with content. 
Zipp, Maher, \& Olson (2017) explain that flipped learning generally use videobased recording technology prepared by the teacher that can access independently before in-class activity. But in the newest age of flipped learning which is flipped learning 3.0, It is all base on the way the teacher applies this strategy. According to Bergmann (2017) flipped learning 3.0 is not static. It means there is no notion that flipped learning is about video and homework like another two current frameworks. The teacher can collaborate with this strategy with the global condition. Besides, the teacher can use their teaching style to apply flipped learning 3.0. It makes flipped learning 3.0 becomes meta-strategy in teaching-learning process. It is the main strategy that determines other strategies used in a certain situation. As a meta-strategy flipped learning 3.0 becomes a foundation strategy that the teacher uses in the teaching processes. It makes the teacher can use their teaching strategy and teaching style which make they can comfort in teaching process. As a meta-strategy, flipped learning 3.0 can transform the entire system of teaching and learning processes if flipped leaning implemented well.

Some studies show that flipped learning gives a good impact on developing speaking performance. In Europe, it was found that Turk students developed their speaking significantly in term of fluency, coherence, grammar, pronunciation, and accuracy, when implemented flipped learning (Köroğlu \& Çakır, 2017). Besides that, Amiryousefi (2019), Quyen \& Loi (2018), Lin \& Hwang (2018), Fan (2018), and Kaur et al., (2018) also investigated the effect of flipped learning in Asia. They found that the good effect of flipped learning toward speaking. All those studies showed the students could improve their speaking by practice routinely and resources that were provided by the teacher and/or the technology that supports their practice. Besides that, learning material that was provided by the teacher makes the students had prior knowledge before entering the class. It made the students could perform better in the class by learning before entering the class.

Despite the positive effect of the flipped learning and self-regulated learning to the students' achievement, flipped learning 3.0 which is the newest age and self-regulated learning has never been conducted for high school in Bali, especially in speaking performance. Moreover, no research collaborates flipped learning 3.0 and self-regulated learning conducted in Bali, especially for speaking performance for tenth-grade students. Thus, the effect remains unclear. Whether it gives a significant difference or not to students' speaking performance. Therefore, in this study, the researcher conducted this study to find out the simple effect and interaction effect of flipped learning 3.0 and selfregulated learning on students speaking performance. There are three research problems in the present study. Those are:

a. Is there any significant difference on the students' speaking performance taught by flipped learning 3.0 than those who are taught by conventional methods on tenth-grade students in SMA Negeri 1 Sukasada?

b. Is there any significant difference on the students' speaking performance those who have high self-regulated learning than those who have low self-regulated learning on tenth-grade students in SMA Negeri 1 Sukasada?

c. Is there any interaction effect between flipped learning 3.0 and self-regulated learning? 


\section{METHOD}

This study was a quasi-experimental study that investigates the simple effect and interaction effect of flipped learning 3.0 and self-regulated learning. Post-test only control group design was chosen as the research design of this study. Two groups were used in this study, namely the experimental group and the control group. The experimental and Control group were given different treatments. The experimental group was taught by flipped learning 3.0 and the control group was taught by the conventional method. In experimental group, flipped learning 3.0 was applied by using three kind of media, namely Schoology, YouTube, and Flipped Grid. In control group, conventional method was applied by teacher center approach

This study was conducted in SMA Negeri 1 Sukasada in the academic year of 2019/2020. Tenth-grade students that learned English as a foreign language were the population of this study. The total of the population of this study was 171 students divided into six classes. Two class was selected randomly by using cluster random sampling. Cluster random sampling was useful when the population members are grouped in units that can be conveniently used as a cluster. As a result, one class became the experimental group that consists of 27 students, and one class became the control group that consists of 26 students.

The data were collected through a survey and a post-test. A survey was used to measure the students' self-regulated, whether they have high or low self-regulated learning. A survey was conducted in the first meeting before the treatment was given. The survey was conducted by distributing the questionnaire to the sample of the research. The questionnaire consisted of 30 points that has five scales. Meanwhile, the Post-test was used to measure the result of the treatment. The type of post-test for both groups was the same in a speaking test. The students should perform in from of the class in the form of conversation in two to three minutes. After the data were collected, it was analyzed by descriptive and inferential analysis. In descriptive statistical analysis, the researcher analyzed mean and standard deviation from the result of the post-test. Meanwhile, in inferential statistical analysis, the researcher used two-way ANOVA to analyze the simple effect and interaction effect of flipped learning 3.0 and self-regulated learning on students' speaking performance. Meanwhile, the effect size was calculated using eta square. The criterion of the effect size used Cohen's (1988) cited in Pallant (2011) that can be seen in the Table 1.

Table 1. The Category of Effect Size

\begin{tabular}{ll}
\hline \multicolumn{1}{c}{ Size } & \multicolumn{1}{c}{$\begin{array}{c}\text { Eta Square } \\
\text { (\% 0f variance explained })\end{array}$} \\
\hline Small & 0.01 or $1 \%$ \\
\hline Medium & 0.06 or $6 \%$ \\
\hline Large & 0.138 or $13.8 \%$ \\
\hline
\end{tabular}




\section{FINDING AND DISCUSSION}

\section{The Finding of Students' Self-Regulated Learning}

Before conducted the treatment, questionnaires were distributed to both the experimental and the control group to find out the students' level of self-regulated learning whether they had a high or low level. To divided the level of students' selfregulated learning, the middle score of the questionnaire was used. It was 102.5. It meant the students who had a higher score than 102.5 classifieds had a high level of SRL, on the other hand, the students who had a lower score than 102.5 classifieds they had a low level of SRL. The result of the students' level of self-regulated learning can be seen in the Table 2 .

Table 2. The Students' Level of Self-Regulated Learning

\begin{tabular}{ccc}
\hline Group & Level of SRL & Total \\
\hline \multirow{3}{*}{ Experimental Group } & High & 15 \\
\cline { 2 - 3 } & Low & 12 \\
\cline { 2 - 3 } & Total & 27 \\
\hline \multirow{2}{*}{ Control Group } & High & 12 \\
\cline { 2 - 3 } & Low & 14 \\
\cline { 2 - 3 } & Total & 26 \\
\hline
\end{tabular}

Based on Table 2, it could be seen that there were fifteen students had a high level of self-regulated learning and twelve students had a low level of self-regulated learning in the experimental group. Meanwhile, in the control group, there were twelve students had a high level of self-regulated learning and fourteen students had a low level of selfregulated learning.

\section{The Finding of the Students' Post Test}

After the data were collected through post-test, the result of the post-test was analyzed by using descriptive statistical analysis and inferential statistical analysis that was helped by SPSS v25. The descriptive statistical analysis was used to summarize and organize the data. The result of descriptive statistical analysis could be seen in the Table 3.

Table 3. Descriptive Statistical Analysis

\begin{tabular}{llrrr}
\hline \multicolumn{5}{c}{ Descriptive Statistics } \\
\hline Model & SRL & Mean & Std. Deviation & N \\
\hline Flipped Learning & Low & 72.33 & 10.012 & 12 \\
\cline { 2 - 5 } & High & 82.40 & 8.659 & 15 \\
\cline { 2 - 5 } & Total & 77.93 & 10.429 & 27 \\
\hline Conventional & Low & 67.71 & 7.760 & 14 \\
\cline { 2 - 5 } & High & 77.00 & 10.938 & 12 \\
\cline { 2 - 5 } & Total & 72.00 & 10.307 & 26 \\
\hline
\end{tabular}




\begin{tabular}{llrrr}
\hline Total & Low & 69.85 & 8.996 & 26 \\
\cline { 2 - 5 } & High & 80.00 & 9.923 & 27 \\
\cline { 2 - 5 } & Total & 75.02 & 10.696 & 53 \\
\hline
\end{tabular}

From table 3, it can be seen the result of speaking performance of experimental and the control group was different. The result of the students' speaking performance who were taught by flipped learning 3.0 was 77.93 mean score and 10.429 standard deviation. Besides, the result of the students' speaking performance who were taught by conventional model was 72.00 mean score and 10.309 standard deviation.

Meanwhile, the result of the students' speaking performance of the students that had high and low level of self- regulated learning was different. The result of students' speaking performance that had high self-regulated learning was 80.00 mean score and 9.923 standard deviation. Besides the result of the students' speaking performance that had low self-regulated learning was 69,85 mean score and 8.990 standard deviation.

After descriptive was done to be conducted, the inferential statistical analysis was conducted to infer and conclude the data by two-way ANOVA test. The result of inferential statistical analysis could be seen in the Table 5.

Table 4. The Result of Two-Way ANOVA Test

\begin{tabular}{|c|c|c|c|c|c|c|}
\hline \multicolumn{7}{|c|}{ Tests of Between-Subjects Effects } \\
\hline \multicolumn{7}{|c|}{ Dependent Variable: Score } \\
\hline \multirow{2}{*}{ Source } & Type III & & & & & \\
\hline & Sum of & $D f$ & Mean & $\mathrm{E}$ & $\mathrm{Sir}$ & Partial Eta \\
\hline \multirow{2}{*}{$\begin{array}{l}\text { Corrected } \\
\text { Model }\end{array}$} & $1697.857^{\mathrm{a}}$ & $\overline{3}$ & 565.952 & 6.523 & .001 & .285 \\
\hline & & & & & & \\
\hline \multirow[t]{2}{*}{ Intercept } & 294226.00 & 1 & 294226.00 & 3391.35 & .000 & .986 \\
\hline & 1 & & 1 & 6 & & \\
\hline Model & 329.376 & $\overline{1}$ & 329.376 & 3.797 & .057 & .072 \\
\hline SRL & 1228.876 & 1 & 1228.876 & 14.164 & .000 & .224 \\
\hline \multirow{2}{*}{$\begin{array}{l}\text { Model } \\
\text { SRL }\end{array}$} & 2.001 & 1 & 2.001 & .023 & .880 & .000 \\
\hline & & & & & & \\
\hline Error & 4251.124 & 49 & 86.758 & & & \\
\hline \multirow[t]{2}{*}{ Total } & 304224.00 & 53 & & & & \\
\hline & 0 & & & & & \\
\hline \multirow{2}{*}{$\begin{array}{l}\text { Corrected } \\
\text { Total }\end{array}$} & 5948.981 & 52 & & & & \\
\hline & & & & & & \\
\hline a. R Squar & 85 (Adju & $\mathrm{R} \mathrm{Sc}$ & $\mathrm{ed}=.24$ & & & \\
\hline
\end{tabular}

The conclusion can be drawn if the significant value is lower than $0.05(<0.05)$, which means that there is a significant difference result of the students' speaking performance based on variable factors. On the other hand, if the significant value is higher than $0.05(>0.05)$, it means that there is no significant difference result of the students' 
speaking performance based on variable factors. Meanwhile, partial eta squared was use to analyze the effect size. In this research, there were three research questions. From Table 4.5 above, the conclusion can be drawn as follow.

Table 4 showed that the significant value of model was higher than 0.05 . The significant value of model was 0.057 . It revealed that there was no significant difference on students speaking performance between students who were taught by flipped learning 3.0 and students who were taught by the conventional method. Meanwhile, partial eta square of flipped learning 3.0 is 0.072 . It is higher than 0.06 . It revealed that there was a medium effect of flipped learning 3.0 on students' speaking performance.

On the other hand, the significant value of self-regulated learning was lower than 0.05 . The significant value of self-regulated learning was 0.000 . It revealed that there was a significant difference on students speaking performance between students who had high self-regulated learning than those who had low self-regulated learning. Besides, the effect size for the self-regulated learning variable that was provided in the column Partial Eta square was 0.224. It revealed there was a large effect of self-regulated learning on students' speaking performance.

Meanwhile, the significant value of the variable Model*SRL was 0.880 . It showed the significant value was higher than 0.05 . It revealed that there was no interaction between flipped learning 3.0 and self-regulated learning. Besides, the result of the effect size of the interaction effect between flipped learning 3.0 and self-regulated learning that was provided in the column labeled Partial Eta squared was 0.000. It was lower than 0.01. It could be classified as a small effect.

\section{The Interaction between Flipped Learning 3.0 and Self-Regulated Learning}

After the data were analyzed through the inferential statistical analysis and effect size, it was found that there was no interaction effect between flipped learning 3.0 and self-regulated learning. During the treatment, there was no interaction between flipped learning and students' self-regulated learning. The students who had high self-regulated learning had better performance in the class whether they taught by flipped learning 3.0 or conventional method. They set their goal in learning and prepared themselves before entering the class by an overview of the material that they would get. It made they were more active in the class whether asking and answering the question. Furthermore, students with high self-regulated learning were more active to practice their speaking and collaborate their idea with their friends. It could develop their speaking performance. The different attitude was shown by the students who had low self-regulated learning. Whether students who were taught by flipped learning 3.0 or conventional method showed low motivation in learning. They were more passive in class. They preferred ignoring their teacher and discussing the topic outside the learning material. They wasted their time practicing their speaking that made them had a bad speaking performance. It could be confirmed that whether flipped learning 3.0 and self-regulated learning 3.0 did not influence each other which made there was no interaction effect. It occurred because self-regulated learning was a very influential student' outcome. 


\section{The Implementation of Flipped Learning 3.0 on Students' Speaking Performance}

Based on the inferential statistical analysis, there was no significant difference on students speaking performance between students who were taught by flipped learning 3.0 and students who were taught by the conventional method. During the treatment, the implementation of flipped learning 3.0 in this research did not work effectively. The media that should support flipped learning 3.0 could not be used as well by the students. Even though it was an important thing in the success of the learning. Unfamiliar media used in the treatment inhibited the improvement of students' speaking performance. The students were difficult to access the learning material that should be learned before entering the class. They had to ask their friends to resend the learning material.

However, the implementation of flipped learning 3.0 did not significantly different in the experimental and control group, because of the media that was used, but overall flipped learning 3.0 gave a good effect on students speaking performance. The experimental group had better performance than the control group. It could be seen from the mean score of the experimental and control groups. The experimental group who was taught by flipped learning 3.0 gained a higher mean score than the experimental group those who were taught by the conventional method. Moreover, the effect size showed a medium effect. They had more ideas to deliver after watching more videos on YouTube. They collaborated their idea and ready-made content material which made their contents were more interesting and more varied. Moreover, they produced their language more accurately. They created their language with appropriate words which made their language organized well.

Furthermore, through the implementation of flipped learning 3.0, the students receive a deeper understanding. They had more time to learn. They had learned and discussed the material provided by the teacher in Schoology before entering the class which made them only asked the point that they did not understand. It allowed the students to create their concept which was easier to be understood. They just needed to get a deeper explanation to fill the gap of the understanding with the other students rather than receive the hole material in the class.

\section{The Implementation of Self-Regulated Learning on Students' Speaking Performance}

The implementation of self-regulated learning on the students gained good results. Based on the result of descriptive and inferential statistical analysis and also effect size, it was found that self-regulated learning gave a significant difference on students' speaking performance between those who had high self-regulated learning and those who had low self-regulated learning. Moreover, the effect size showed a large effect.

During the treatment in this research, the students with high self-regulated learning did a better performance in the class. They prepared themselves before entering the class by learning the material and remembering their prior knowledge about that material. It made they were more ready to follow the class. They knew what they need to be asked in the class to get a deeper explanation from the teacher. It made the students who had high self-regulated learning was more active in the class. They could control themselves to achieve their goal in learning. They did more interaction in the class to ask and answer the question frequently that made the class more alive. Besides that, the 
students who had high self-regulated learning applied their knowledge in the class. They practiced to master the material and develop their speaking. Furthermore, the students who had high self-regulated learning evaluated and reflected themselves after performing in front of the class. They assessed themselves to know their weakness and strength about that material. They would improve their weakness and use their strength to cover their weakness. Besides that, they also used feedback from their friend and the teacher to evaluate their speaking performance. These feedbacks were needed by the students to improve their speaking. Sometimes, the students could not assess themselves to find their weakness which made the feedback was very important for the students.

\section{CONCLUSION AND SUGGESTION}

The aim of this study was to investigate the main effect and interaction of flipped learning 3.0 and self-regulated learning on students speaking performance. The result showed that flipped learning 3.0 gave a positive effect on students' speaking performance but it was not significant. The use of teaching media was the main problem. The students were could not be easy to access the learning material because of the unfamiliar media. However, the implementation of flipped learning 3.0 did not give significantly different, but it gave a positive effect on the students. The students were easier to understand the learning material that is given before the class time which made the teacher only gave a deep explanation and fill the gap between the students.

Besides, self-regulated learning gave a significant difference on students speaking performance. The students were highly influenced by their self-regulation in the learning process. Students with high SRL were active in the learning process. They prepared themselves as well. It made they could perform batter in the class. Moreover, they reflect their learning which made them know their weakness that could be improved. The students with high and low SRL differed visibly in their use of strategies, especially in cognitive learning strategies, their awareness and readiness to learn, and the use of time, resources and peer support.

Meanwhile, there was no interaction effect between flipped learning 3.0 and selfregulated learning. Self-regulated learning highly influences students' outcomes which implemented flipped learning that could not gave a positive effect on the students with low SRL. The student with high SRL was actively in the class whether they were taught by flipped learning 3.0 or conventional method. On the other hand, the students were very passive in the learning process in both classes.

Besides, this study has certain limitations that need to be addressed. Because of the lack of implementation time, the findings in this study may not fully represent the effect of inverted classroom implementation in students' speaking performance. More time in implementing flipped learning and self-regulated learning is needed for further research in the same field. The second limitation is that the data for this study were only analyzed through a quantitative approach. It is recommended to apply qualitative approaches such as classroom observation and interviews to gain a deeper understanding of students' perceptions. 


\section{REFERENCES}

Abrar, M., Mukminin, A., Habibi, A., Asyrafi, F., Makmur, M., \& Marzulina, L. (2018). "If our English isn't a language, what is it?" Indonesian EFL Student Teachers' Challenges Speaking English. Qualitative Report, 23(1), 129-145.

Amiryousefi, M. (2019). The incorporation of flipped learning into conventional classes to enhance EFL learners ' L2 speaking, L2 listening, and engagement. Innovation in Language Learning and Teaching, 13,(2), 147-161. https://doi.org/10.1080/17501229.2017.1394307

Bergmann, J. (2017). Flipped Learning 3.0: Flipped Learning Will Never be the Same. www.yotube.com. https://www.youtube.com/watch?v=gppL3mw8SsU

Bergmann, J., \& Sams, A. (2012). Flip Your Classroom. Jonathan Bergmann.

Carneiro, R., Lefrere, P., Steffens, K., Underwood, J. (Eds). (2011). Self-Regulated Learning in Technology Enhanced Learning Environments (Vol 5). Rotterdam/ Boston/ Taipei: Sense Publisher.

Fan, X. (2018). Research on Oral English Flipped Classroom Project- based Teaching Model Based on Cooperative Learning in China. Educational Sciences: Theory \& Practice, 18 (5), 1988-1998.

Geduld, B. (2016). Exploring Differences Between Self-Regulated Learning Strategies of High and Low Achievers in Open Distance Learning. Africa Education Review, 13(1), 164-181.

Handoko, M. D. (2017). Concept of Speaking Performance. Iqro Metro. http://iqrometro.co.id/concept-of-speaking-performance.html

Kaur, C., Singh, S., Singh, H., Jaswant, S., Singh, T., Singh, M., \& Ja, H. (2018). Flipped Classroom Approach for Improving Speaking Skills of TVET Trainees. International Journal of Applied Linguistics \& English Literature, 7 (7), 27-39.

Kızıl, A. Ş., \& Savran, Z. (2018). Assessing Self-Regulated Learning: The Case of Vocabulary Learning Through Information and Communication Technologies. Computer assissted Language Learning, $31 \quad$ (5-6), 599-616. https://doi.org/10.1080/09588221.2018.1428201

Köroğlu, Z. C., \& Çakır, A (2017). Implementation of Flipped Instruction in Language Classrooms : An Alternative Way to Develop Speaking Skills of Pre-Service English Language Teachers. International ournal of Education and Development Using Information and Communication Technology, 13 (2), 42-55.

Lin, C., \& Hwang, G. (2018). A Learning Analytics Approach to Investigating Factors Affecting EFL $S$ tudents ' Oral Performance in a Flipped Classroom. Education Technology \& Society, 21 (2), 205-219.

Pallant, J. (2011). For the SPSS Survival Manual website, go to www.allenandunwin.com/spss This is what readers from around the world say about the SPSS Survival Manual:

Quyen, T. T. T., \& Loi, N. V. (2018). Flipped model for improving students' English speaking performance. Can Tho University Journal of Science. https://doi.org/10.22144/ctu.jen.2018.012 
Wael.A., Asnur. M. N. A., \& Ibrahim. I. (2018). Exploring Students' Learning Strategies in Speaking. International Journal of Language and Education, 2 (1), 65-71.

Wang, H., \& Chen, C. W. (2019). Learning English from YouTubers: English L2 Learners' Self-Regulated Language Learning on YouTube. Innovation in Language Learning and Teaching, $O(0), 1-14$.

Zipp, G. P., Maher, C., \& Olson, V. (2017.). SOLO-Framed Flipped Learning Environment: "Speaking the Language of Today's Learner". Journal of Physical Therapy Education, 31 (3). 